\title{
SEX-DIFFERENCES IN ATTITUDE TOWARDS MATHEMATICS OF JUNIOR HIGH SCHOOL STUDENTS IN GHANA
}

\author{
Nyala, Joseph Issah \\ Department of Mathematics Education \\ University of Education \\ Winneba. Ghana.
}


Sex Differences n Attitude towards Mathematics

\section{Abstract}

The study investigated junior high School (JHS) students' attitudes that affect their study of mathematics. Five hundred and eighty-one students selected from nine junior high schools in the Cape Coast Municipality in Ghana were involved in the study. The results of the analyses showed that both boys and girls at the JHS level had positive attitudes towards mathematics in all eight attitudinal dimensions. Both sexes did not see mathematics as a male dominated domain, with girls seeing it less a male domain than boys. Of the attitude variables, confidence in learning mathematics, mathematics anxiety and success in mathematics correlated most positively and significantly with the rest of the variables. A number of implications of the findings for improving JSS students' attitudes are discussed.

\section{Introduction}

In contrast with findings regarding achievement, studies of students' attitudes to mathematics consistently show significant gender differences favouring males. These studies cover both primary and secondary students and measure a range of affective variables such as self-confidence, interest, enjoyment, self-efficacy and selfconcepts. Only for anxiety do females significantly outscore males (Thomson, Cresswell and De Bortolli, 2004).

A study of students' attitudes towards mathematics will inform parents, teachers and mathematics educators on the gravity of students' inclination towards the subject. Studies have shown that one's attitudes towards the subject affect ones' achievement in it.

Confidence in learning mathematics, or the degree to which a person feels certain of his/her ability to do well in mathematics, has consistently emerged as an important component of gender -related differences (Casey et al, 2001, Vermeer et al, 2000). Generally, confidence in mathematics has been associated with mathematics achievement (Ryan \& Pintrich, 1997), with correlation coefficients 
ranging from 0.3 to 0.4 (Hart, 1989; Newman, 1990; Ryan \& Pintrich, 1997). For example, Ryan and Pintrich (1997) showed that students who perceived themselves as cognitively competent were less likely to avoid seeking help, whereas, students who were unsure of themselves were more likely to feel threatened when asking their peers for help and more likely to avoid seeking help. They explained that students with high confidence in mathematics do not attribute their need for help to lack of ability and thus are more likely to seek help when they need it.

Vermeer et al (2000) have shown that the gender differences in self confidence were more marked for application problems than computation problems, with girls showing significantly lower confidence for application problems. Eshun et al (1999) found that in Ghana, girls in mixed schools expressed the least success and confidence in doing mathematics as well as having higher mathematics anxiety. This is consistent with findings by Thomson and Fleming (2004) that girls underestimate their own ability to solve mathematics problems due to lack of confidence and mathematics anxiety. Despite such consistent findings of Ghanaian girls' low confidence in mathematics, studies of classroom environment have shown that the girls' confidence in mathematics improved greatly in classes which actively involved girls in the learning of mathematics (Boaler, 2000; 1997; Rennie \& Parker, 1997). It is, however, important to note that numerous studies demonstrate the importance of factors such as confidence (Fennema and Sherman 1978; Meyer and Koehler 1990); sex-role stereotyping of mathematics as a masculine domain (Baker 1983; Boswell 1985); and belief in the importance of mathematics (McLeod 1989).

Eshun et at (1999) also reported that in general, students had positive attitudes towards mathematics especially along the attitudinal variables, "usefulness of mathematics", "like mathematics" and "success in doing mathematics". They revealed that students are however least positive about "effective motivation" and "confidence in doing mathematics". They concluded that students' low achievement in mathematics could partly be attributed to lack of 
motivation and confidence to learn the subject. It can be observed that attitude seems to play a substantial role in one's inclination towards mathematics. This study sought to determine sex differences in attitude towards mathematics of Ghanaian JHS students so as to obtain an explanation for the way they behave when issues concerning mathematics are mentioned.

\section{Purpose of the Study}

The purpose of this study was to investigate Ghanaian JHS students' attitudes towards mathematics, and determine any relationships between the attitudinal variables so as to find out which attitudinal variables contribute most to boys' and girls' attitudes towards mathematics.

\section{Research Questions}

The following research questions were formulated:

1. What attitudes do Ghanaian Junior High School pupils have towards mathematics?

2. Is there any relationship between the various attitudinal variables?

\section{Significance of the Study}

The study sought to provide information on gender differences in attitude towards mathematics so as to enable teachers:

- Devise means of improving on mathematics teaching to cater for both sexes of students;

- Provide a reference through which parents' and teacher's attitudes towards mathematic may be changed, particularly labelling mathematics as "masculine" or "feminine";

- Add to the existing body of knowledge in the area of gender differences in attitude towards mathematics at the Junior High School level and other higher levels of study in Ghana. 


\section{Methodology}

Population and sampling

The targeted population for the study was Junior high School (JHS) pupils in Ghana. The sample was taken from the final year group of Junior high schools in Ghana.

The sample comprised five hundred and eighty-one (581) pupils from nine (9) schools of the Cape Coast Municipality. Of the schools, one was a boarding JHS, and two private JHS all in Cape Coast in the Central Region of Ghana. The rest were either of single-sex male, single-sex female or mixed and public type schools. There were either the single-stream or double stream set-up where some schools ran shift and others did not. The breakdown is shown in tables 1 and 2.

Table I: Distribution of Pupils by Type of School

\begin{tabular}{|ll|}
\hline \multicolumn{1}{|c|}{ Type } & Number \\
\hline Single-sex male & 61 \\
Single-sex female & 158 \\
Mixed Male & 172 \\
Mixed Female & 190 \\
\hline Total & 581 \\
\hline
\end{tabular}

In addition to the above considerations for selection of the sample, schools were also selected based on their being boarding schools or day schools. The location of the school in terms of nearness to a particular category of inmates was also considered. Some school are sited close to residential areas where inmates have adequate educational facilities, while others are sited close to low income earners who may not care much about their children's education. This manner of choice of sample provided schools and students with varied backgrounds.

For the schools, cognisance was taken of their past records. A cross-section of schools was taken to obtain a sample of schools 
with high academic standing, average academic standing and below average standing.

Permission was sought from the Headmasters (J)/Headmistresses (J) to conduct the study. A period, convenient to all schools involved was worked out, and three research assistants trained to assist in the data collection.

The final year students of the Junior High Schools were selected for the study because it was conducted at a period close to their final Basic Education Certificate Examination (BECE). It was hoped that they had studied enough of mathematics by then. Giving an opinion about mathematics at such a time was timely as they had built their impressions of the subject by then.

The selection procedure described above was used so as to suit the descriptive survey type of study chosen. As pointed out by Gay (1987), this design involves collecting data in order to test hypotheses or to answer questions concerning the current status of the subjects of study. This type of study provides a descriptive picture of a situation to establish norms and baseline data for consideration by research practitioners in making their decisions to help raise relevant questions, or identify needed research.

\section{Instrument}

The instrument employed for the data collection was Attitudinal Questionnaire Items (AQI).

The Likert scale was followed in preparing the questionnaire. This scale is based on statements that are classified as positive or negative. Each statement has five options of which one was selected according to the respondent's feelings. Weights of 1, 2, 3, 4 and 5 were attached to the options: Strongly disagree (SD)", "Disagree (D)", Undecided (U)", Agree (A)", and "Strong Agree (SA)" respectively when the statement is positive. This was reversed for a negative statement. For instance, to a positive statement, "one can use mathematics in daily life", if a response is SA, it received a weight of five. However, to a negative statement, "it is useless for females to learn mathematics" if a response is SA, it received a 
weight of one. A neutral response of "undecided $(U)$ " to each item gained a mean weight of three. Any mean weight above three was taken to indicate a positive attitude whilst a mean weight below three suggested a negative attitude.

Participants were made to respond to sixty-one items comprising, ten items on the respondent's background, and fifty-one items on respondent's attitude towards mathematics of the questionnaire's close-ended items. Subjects were to provide a tick $(\sqrt{ })$ or write down the most appropriate initials of the pre-printed responses of each item.

Eight attitudinal variables, each regarded as a dimension along which a score reflected positive or negative attitude of a student were tested for the study as:

1. Usefulness of Mathematics, 2. Confidence in Mathematics, 3. Success in Mathematics, 4. Effective motivation, 5. Mathematics anxiety, 6. Mathematics as a male domain, 7. Understanding Mathematics, and 8 . Like doing mathematics problems.

\section{Validity of the Instrument}

The attitude questionnaire items were extracted from Nkani (1993), and Eshun (1990, 1999). These are items that had already been tested with senior high school students and found to be highly valid. The extracted items were only modified and reformed to suit the Junior High school students. As stated by Nkani (1993), content validity is related to how adequate the content of the items sampled the domain about which inferences are made.

Experts in the field of measurement and Research Methods in Education assisted in determining the suitability of the extracted items and found them suitable for the study. 


\section{Reliability Co-efficient}

The reliability coefficient of the questionnaire items was found using the method of Cronbach Alpha on the computer. The alpha value of the questionnaire items was 0.63

Table 3 shows the attitudinal variables and typical items in the questionnaire that reflect the attitude being measured.

Table 3: Attitude Variables and typical Items

\begin{tabular}{|cl|}
\hline Item & \multicolumn{1}{c|}{ Variable } \\
11 & Usefulness of mathematics \\
45 & Usefulness of mathematics \\
60 & Success in Mathematics \\
12 & Effective motivation \\
15 & Mathematics Anxiety \\
17 & Mathematics as male Domain \\
45 & Understanding Mathematics \\
53 & Like Mathematics \\
\hline
\end{tabular}

Statements that correspond to the attitude variables stated in table 3 are as follows:

11. Mathematics is the most useful subject of all.

57. I like mathematics because you can figure things out instead of memorizing.

60. I don't think mathematics is fun but I always want to do well in it.

12. Studying mathematics gives me enormous pleasure.

15. I am always under a terrible pressure in mathematics class.

17. Boys need mathematics in life more than girls.

45. It takes me too much time to understand any idea in mathematics.

53. Mathematics thrills me, and I like it better than any other subject. 


\section{Data Collection Procedure}

After the schools had fixed days on which they wanted to have the study, a schedule was prepared making sure that schools along the same locality did not write the test many days before each other to avoid a situation of response readiness, if they have prior knowledge of the questions before responding to them.

Ample time was allowed for answering questions from the questionnaires provided and respondents were assisted by research assistants to answer the questionnaire items. The answered scripts were collected after they had finished responding to them.

\section{Data Analysis}

The students were given index numbers to be used for the questionnaire. As stated earlier, eight main groups of independent dimensions or variables were classified from the questionnaire items. Each dimension consisted of a collection of the various items into a unit that pointed to specific aspects of attitude towards mathematics. For instance, "how would you be encouraged to do mathematics if you are always under terrible pressure in mathematics class?" suggests a feeling of mathematics anxiety while, "how would you be encouraged to do mathematics if you are well informed about careers that require mathematics?" suggests the factor, "career influence". For an increased internal consistency of the questionnaire, a mixture of positive and negative statements was included. Table 4 shows a classification of the questionnaire items into units.

Under each dimension, the mean of the weights attached to each item were found using the computer. This was recorded by type of school and sex for the attitude variables. 
Kruskal-Wallis analysis of variance was used to compute and test whether there were any significant differences between the mean responses of

i. $\quad$ girls in single-sex schools and boys in mixed schools

ii. girls in single-sex schools and girls in mixed schools

iii. girls in single-sex schools and boys in single-sex schools

iv. boys in mixed schools and girls in mixed schools

v. boys in mixed schools and girls in both mixed and single-sex schools.

Table 4: Questionnaire items contributing to the various dimensions by nature of statement

Attitude Variable Statement

Usefulness of Maths

Confidence in Maths

Success in Maths

Effective Motivation

Mathematics Anxiety

Maths as Male Domain

Understanding Maths

Like Maths (Problems)

Positive
11, 22, 29, 30, 32

24

44,46

12,45

$15,21,28,36,46$

$17,33,38,41,43$

$19,27,38,37,51,40$
Negative

$26,36,37,29,34$

25,34

23,48

9,21

20

$14,31,49$

The Pearson Product-moment correlation coefficient ® ${ }^{\circledR}$ was used to obtain a value that helped to describe the degree of relation between the attitude variables.

\section{Results}

About two-fifths, representing $40 \%$ of the respondents were males whilst three-fifths, representing $60 \%$ of respondents were females. In most cases, more females appear to shy away from mathematics than their male counterparts. The selection was therefore to yield a proportional representation of a higher representation from females than males in attitude towards mathematics. Of the males, there were more males in mixed schools than males in single-sex schools. 
This was intended to find out whether the presence of females would have any effect on the males. Of the females, there were more females in mixed schools than females in single-sex schools.

The average age of respondents was found to be 15.0 years. Only one pupil was ten years old whilst 19 pupils were aged 18. The highest number of respondents was for the age of 15 years. This implies that much as there were a few respondents with ages falling outside the expected age range of 14 to 16 , the majority fell within the age range. Of those wishing to proceed to the senior high school (SHS), 95.4\% responded in the affirmative. Only $3.4 \%$ would not want to proceed to the SHS. This implies that majority of the students in the study would want to study at the SHS. To the vital question, "will you like to do elective mathematics at the SHS, $67.6 \%$ expressed the desire to study the subject. Of this percentage, $41.8 \%$ were females and $25.8 \%$ were males. Thus, more females intended and planned for elective mathematics at this stage. This implies that females would end up dominating in mathematics related courses at higher levels if they are encouraged to do so.

\section{Attitude}

Table 5 shows the means of scores on the eight attitude dimensions by type of school and sex. The table shows that the mean scores for all students in the population were above three for six out of the eight attitude variables. This is an indication that the students selected more positive items of the attitude dimensions. The most positive responses were for "usefulness of mathematics", "like mathematics" and "success in mathematics", in that order. It can be observed from the table that students in mixed schools selected more positive responses on attitudes towards mathematics in all eight dimensions than students in single-sex schools. None of the sexes regarded mathematics as a male domain, but females saw mathematics as less a male domain than males. Females in mixed schools indicated more mathematics anxiety, whilst students in 
single-sex schools indicated less mathematics anxiety. Students were undecided about their confidence in studying mathematics.

Table 5: Means of attitude scores by type of school and sex

\begin{tabular}{|llllll|}
\hline Attitude & $\begin{array}{l}\text { Single- } \\
\text { Sex }\end{array}$ & $\begin{array}{l}\text { Single- } \\
\text { Sex }\end{array}$ & $\begin{array}{l}\text { Mixed } \\
\text { Variable }\end{array}$ & $\begin{array}{l}\text { Mixed } \\
\text { (Memale) }\end{array}$ & $\begin{array}{l}\text { (Male) } \\
\text { (Female) }\end{array}$ \\
Usefulness & 3.67 & 3.81 & 3.78 & 3.87 & 3.77 \\
Confidence & 2.99 & 3.05 & 2.97 & 3.02 & 3.01 \\
Success & 3.24 & 3.43 & 3.41 & 3.39 & 3.37 \\
Effective Mot & 3.02 & 2.98 & 3.04 & 3.03 & 3.02 \\
Maths Anxiety & 2.80 & 2.91 & 2.91 & 3.05 & 2.92 \\
Male Domain & 2.83 & 2.36 & 2.56 & 2.40 & 2.54 \\
Understanding & 3.68 & 2.98 & 3.16 & 3.22 & 3.26 \\
Like Maths & 3.45 & 3.53 & 3.29 & 3.41 & 3.42 \\
\hline
\end{tabular}

For a closer look at the responses, each attitude variable was observed in relation to students' responses.

\section{Usefulness of Mathematics}

The mean numerical value for all categories of respondents was above three. The largest positive mean was by females, with females in mixed schools agreeing more to the usefulness of mathematics than females in single-sex schools. On the whole, males could not agree as much as females. Males in mixed schools had a higher mean response than males in single-sex schools. This suggests that males in mixed schools agree more that mathematics can be applied in their daily lives, and contributes greatly to science and other fields of knowledge than males in single-sex schools.

\section{Confidence in Learning Mathematics}

The mean numerical value of responses to this variable was 3.01. This was however close to stating that respondents were undecided about their confidence in learning mathematics as most of them stated that word problems in mathematics are frustrating. 
Females had slight confidence in learning mathematics than males, as the former registered a mean value of 3.04. This is contrary to the assertion by (Casey et al, 2001; Hyde et al, 1990; Ma, \& Kishor, 1997; Sayers, 1994; Vermeer et al, 2000) that compared with boys, girls lacked confidence, had debilitating causal attribution patterns, perceived mathematics as a male domain, and were anxious about mathematics. Males on the contrary registered a mean value of 2.98. Males in mixed schools recorded a lower mean response than males in single-sex schools. The low gender difference in confidence suggests that at the JHS level there were no significant differences in confidence between the boys and girls.

\section{Success in Mathematics}

Both males and females expressed positive attitudes towards success in mathematics as they all registered mean values above three. This is an indication that students agree that success in mathematics spurs them more to study the subject. Females in single-sex schools registered the most positive mean value. Males in single-sex schools registered the least positive mean value of 3.24. Thus, males in mixed schools believed more that they could have success in mathematics than those in single sex schools; as the former registered a higher positive mean value. These results suggest that success in mathematics is the desire of all categories of students.

\section{Effective Motivation}

The overall mean response was a little above three, with males in mixed schools registering the highest mean value. The results show that students were neither encouraged nor discouraged to do mathematics. However, females in single-sex schools indicated the feeling that they were not motivated enough to study mathematics as they registered the only mean value less than three, a value of 2.98. Thus the mean responses to the variable, effective motivation 
in mathematics indicated that males felt more motivated in mathematics than females.

\section{Mathematics Anxiety.}

The results of this variable showed that respondents did not have any mathematics anxiety as they registered an overall mean value of less than three. Females in mixed schools registered the only mean value above three. Thus, they seemed to express a slight anxiety in their approach to mathematics. The results of this variable indicate that females in mixed schools are not quite confident of their ability to do well independently, hence their apprehension towards mathematics.

\section{Mathematics as a Male Domain}

Both sexes did not see mathematics as a subject reserved only for males. Each category recorded mean values less than three, with the least mean value of 2.36 coming from females in single-sex schools. Females in mixed schools were the next to register their disagreement that boys need mathematics in life more than girls do. Males in mixed schools registered a mean value of 2.56 , whilst males in single-sex schools registered a mean value of 2.83 . Though less than three, these mean values appeared closer to the neutral value of three than the mean values of their female counterparts. The differences seemed to reflect the feeling harboured by males that mathematics is more appropriate to them than females,

\section{Understanding Mathematics}

The overall response to this variable registered a mean value above three. However, females in single-sex schools registered the only mean value less than three. This is an indication that females in single-sex schools expressed the feeling that mathematics seems unusually hard for them and that it takes them too much time to understand any idea in the subject. The highest mean value was 
recorded by males in single-sex schools. On the whole, males registered a higher mean response than females. This meant females felt they did not understand mathematics whilst males thought they did.

\section{Like Mathematics (Problems)}

There was an overall mean response of more than three for this variable. This suggests that both sexes agree that working as a mathematician is as interesting as any other job, and that they liked solving problems that use ideas from several parts of the syllabus. The highest mean value was recorded by females in single-sex schools, whilst the lowest by males in mixed schools. For this variable, females were more positive than males. Thus females saw mathematics as enjoyable and that they did not find any difficulty in solving mathematics problems on their own.

\section{The relationship between categories of respondents in attitude variables}

Kruskal-Wallis test was used to compute a value that would help determine whether there are any significant differences among the ranks of the four categories of respondents in the attitude variables, after their mean responses were ranked.

The value obtained from the test statistic was 0.26 . It was observed that since the calculated value of 0.26 is less than 7.81 , the null hypothesis could not be rejected and conclude that there are no significant differences in ranks of mean responses of the four categories of respondents in attitude variables. One therefore concludes that the order in which the various categories of students expressed positive attitudes towards mathematics was the same.

\section{Relationship between the attitudinal variables}

In order that all variables are catered for on the table, abbreviations were used in place of the variables as follows: 
UM denotes usefulness of mathematics

$\mathrm{CM}$ denotes confidence in learning mathematics

SM denotes success in mathematics

EM denotes effective motivation in mathematics

MA denotes mathematics anxiety

MD denotes mathematics as a male domain

DM denotes understanding mathematics, and

LM denotes Like Mathematics problems.

These abbreviations are used throughout the rest of this study.

To enable relationships be established between the various attitudinal variables, the Pearson Product-Moment correlation Coefficients between pairs of varieties were found. Table 6 shows a matrix of correlation coefficients between the scores of the various attitudinal variables for all respondents in the study.

The table shows that the variables, confidence in learning mathematics $(\mathrm{CM})$, success in mathematics (SM) and mathematics anxiety (MA) correlated positively and significantly with the other variables. This meant that an increased exhibition of any one of these variables would yield a corresponding portrayal of the other variables. Thus a student who showed signs of these attitudes (confidence, success and mathematics anxiety) also had a potential to exhibit the remaining. The most positive and significant correlation coefficients were between confidence in learning mathematics (CM) and the variables, success in mathematics (SM), mathematics anxiety (MA) and like doing Mathematics Problems (LM). 
Sex Differences n Attitude towards Mathematics

Table 6: Correlation Coefficients between Attitudinal Variables for all respondents

\begin{tabular}{|c|c|c|c|c|c|c|c|c|}
\hline \multirow[b]{2}{*}{ 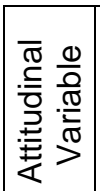 } & \multirow[b]{2}{*}{ UM } & \multirow[b]{2}{*}{ CM } & \multirow[b]{2}{*}{ SM } & \multirow[b]{2}{*}{ EM } & \multirow[b]{2}{*}{ MA } & \multirow[b]{2}{*}{ MD } & \multirow[b]{2}{*}{ DM } & \multirow[b]{2}{*}{ LM } \\
\hline & & & & & & & & \\
\hline UM & - & -0.013 & 0.040 & 0.019 & 0.005 & $0.098^{*}$ & $0.085^{\star}$ & $0164^{\star \star}$ \\
\hline CM & & - & $-0.369^{\star \star}$ & 0.023 & $0.376^{\star *}$ & $0.244^{* *}$ & $0.251^{\star *}$ & $0.373^{* *}$ \\
\hline SM & & & - & $0.116^{\star *}$ & $0.197^{\star \star}$ & $0.144^{\star \star}$ & $0.127^{* *}$ & $0.085^{* *}$ \\
\hline EM & & & & - & 0.043 & 0.001 & 0,035 & -0.017 \\
\hline MA & & & & & - & $0.273^{\star *}$ & $0.229^{\star *}$ & 0.243 \\
\hline MD & & & & & & - & $0.219^{* *}$ & 0.052 \\
\hline $\mathrm{DM}$ & & & & & & & - & $0.127^{\star \star}$ \\
\hline LM & & & & & & & & - \\
\hline
\end{tabular}

${ }^{*}$ Correlation is significant at the 0.05 level

** Correlation is significant at the 0.01 level

Usefulness of mathematics (UM) however correlated negatively with the variables, confidence in learning mathematics (CM), Mathematics as a male domain (MD) and understanding mathematics (DM). There were negative and significant correlation coefficients between the variables, usefulness of mathematics (IJM) on one side, and mathematics as a male domain (MD) and understanding mathematics (DM) on the other side, as well as between the variables, confidence in learning mathematics (CM) and success in mathematics (SM). This implies that on the whole, the responses of students were consistent among all attitude variable in the study except the variable usefulness of mathematics (UM).

\section{Discussions}

In testing whether there was any significant difference in attitudes of male and female JHS students towards mathematics, it was found that there was no significant difference in attitudes towards mathematics of males and females at the JHS level. This indicated that both sexes of students have the same feelings towards 
mathematics. They all see the usefulness of mathematics, like studying mathematics, experience success in mathematics, and understand mathematics.

The finding that both sexes of students showed the same feelings towards mathematics is consistent with studies of classroom environment which have shown that the girls' confidence in mathematics improved greatly in classes which actively involved girls in the learning of mathematics (Boaler, 2000; 1997; Rennie \& Parker, 1997). Since this study involved various classroom settings, this might be a cause of such results. Eshun (1991) also found no sex related differences during elementary school years at most affective levels. The indication therefore is that both sexes of students expressed high desires to study elective mathematics at the senior secondary school. This is also corroborated by Brush (1990), Sherman (1980), Heller and Parsons (1981) that girl's confidence in their ability tends to match that of boys in the primary years.

Males and females did not consider mathematics as a male domain. This is contrary to findings that compared with boys, girls perceived mathematics as a male domain, and were anxious about mathematics (Casey et al, 2001; Hyde et al, 1990; Ma, \& Kishor, 1997; Sayers, 1994; Vermeer et al, 2000). There suggests that JHS boys and girls in Ghana express similar feelings towards the subject. It was found that though both sexes expressed enjoyment in studying mathematics, females in single-sex schools showed that they enjoyed studying the subject more than males and females in mixed schools, and males in single-sex schools. The finding that females in single-sex schools enjoyed studying mathematics is consistent with findings by Forgasz \& Leder, (1996); Norton \& Rennie, (1998) that students in single sex schools were found to have more positive attitudes than students in the mixed schools. This is an indication that such environments provide girls with freer feelings to discuss their needs. They also tend to show more sympathy for one another. This implies that a single-sex 
environment is more academically friendly for female students and they would benefit better from such an environment.

Females expressed more confidence in learning mathematics than males. This finding is again contrary to findings by (Casey et al, 2001; Hyde et al, 1990; Ma, \& Kishor, 1997; Sayers, 1994; Vermeer et al, 2000) that compared with boys, girls lacked confidence, had debilitating causal attribution patterns, perceived mathematics as a male domain, and were anxious about mathematics. Females in single-sex schools expressed more confidence in learning mathematics than females in mixed schools. Males in single-sex schools also expressed more confidence in learning mathematics than males in mixed schools. Thus, students in single-sex schools showed more confidence in learning mathematics than those in mixed schools. This finding is consistent with findings by Lee and Rudyk (1986) as they found that students in single-sex schools showed higher achievement and higher educational aspirations than their counterparts in coeducational schools. An implication to the higher confidence by students in single-sex schools could be teachers' interest in these groups than the mixed, as evidenced in findings by Parsons, Alder and Kaczala (1982) that children's attitudes were influenced more by parents' and teachers' attitudes than by their own past performances.

\section{Recommendations}

In the light of the above research findings, the following recommendations have been made:

- Teachers, parents and mathematics educators should encourage both sexes of students to learn elective mathematics at the SHS. In particular, parents should support their wards to do mathematics in the JHS and SHS by arranging extra tuition for them after school hours.

- Communities or organizations that might want to establish single-sex schools in the country should be encouraged to do so, as the results of this study indicate 
a more positive attitude by students in single-sex schools than those in mixed schools.

- Mathematics clubs should be encouraged at all levels and made to function actively from primary school to other higher levels to provide an early start in the practice of the subject. This study found that students would opt to study elective mathematics if they are assured that these clubs would be formed and made to function well.

- Parents and guardians also need more education on the relevance and career opportunities of the subject. They can then be in a better position to educate those who are not aware of its relevance. They will then encourage their children to take the study of the subject more seriously. As can be observed from the findings, students indicated that they needed more encouragement and support from their parents and guardians. Also parents' attitudes towards mathematics can influence their wards' choice of the subject. Information to parents and guardians could be given on television and radio programs, or by the use of information vans and other information transmitting systems.

- While some students developed negative views about mathematics, certain categories of students remained confident and retained their interest in mathematics. This indicates that there are students out there who would offer mathematics to higher levels when given the encouragement. This finding signals the need for future work for those more generally committed to improving boys' and girls' chances in mathematics, to examine the interaction of class and sex in the mathematics classroom.

- This study should also be replicated for JHS schools in other Regions of Ghana as this study was conducted 
only in selected schools in the Cape Coast Municipality. This should include schools in both urban and rural areas so as to provide inter-regional comparisons in order to provide a basis for more general conclusions about sex differences in attitudes towards mathematics.

- Teachers need to exercise more tolerance, patience and sympathy towards students in mathematics classrooms as most of the students indicated that they would rather learn better under such teachers.

\section{References}

Baker, D. R. (1983) Can the Difference between Male and Female Science Majors Account for the Low Numbers of Women at the Doctoral Level of Science? Journal of College and Student Teaching 13(2):102-107.

Bell, L and Hyde, J. S (1983). Why Gender Differences are Important. In Hazel, C (1998). A Comparison of Genderrelated Attitudes towards Mathematics between Girls in Single-sex and Co-educational Schools. Submitted to the University of Exeter for the degree of Master of Education.

Boaler, J. (1997). Experiencing school mathematics: Teaching styles, sex and setting. Buckingham: Open University Press.

Boaler, J. (2000). So girls don't really understand mathematics? Dangerous dichotomies in gender research. Paper presented at the 9th International Congress of Mathematics Education (ICME-9). Tokyo.

Boswell, S. L. (1985). The Influence of Sex-Role Stereotyping on Women's Attitudes and Achievement in Mathematics. In: Women and Mathematics: Balancing the Equation, edited by S.F. Chipman, L. R. Brush and D. M. Wilson. Pp. 175-197. Hillsdale, $\mathrm{N}$ J: Lawrence Erlbaum.

Brush, L. R (1990). Encouraging Girls in Mathematics: The Problem and the Solution. (Cambridge, MA, ABT Associates) 
Casey, M. B., Nuttall, R. L., \& Pezaris, E. ( 2001). Spatial mechanical reasoning skills versus mathematical selfconfidence as mediators of gender differences on mathematics subtests using cross-national gender-based items. Journal for Research in Mathematics Education, 32(1), 28-57.

Catsambis, S. (1994). "The Path to Math: Gender and Racial -Ethnic Differences in Mathematics Participation from Middle School to High School." Sociology of Education 67:199-215

Ernest, P. [1991]. Educational Research, It's Philosophy and Purpose. An introduction to Research Methodology and Paradigms. Exeter

Eshun, B. A. (1990). Sex-related Differences in Mathematics Achievement of Secondary School Students, University of Cape Coast. Ghana.

Eshun, B. A (1999, 2000). Pattern of Mathematical Achievement of Secondary School Students in Ghana. Journal of Mathematics Education, 2(1)22-33.

Fennema, E. and Sherman, J. [1978]. Sex-related differences in mathematics achievement and related factors: A further study. Journal for Research in Mathematics Education, 9 [3], $189-203$.

Fennema, E. [1979]. Teacher's attributions and beliefs about girls, boys and mathematics. Educational Studies in Mathematics. In Eshun B. A (2000). Pattern of Mathematical Achievement of Secondary School students in Ghana. Journal of Science and Mathematics Education. 2(1)22-33

Fisher, D. \& Richards, T. (1998). Association between teacherstudent interpersonal behaviour and student attitude to mathematics. Mathematics Education Research Journal, 10(1), 3-15.

Forgasz, H. \& Leder, G. (1996). Mathematics classrooms, gender and affect. Mathematics Education Research Journal, 8(2), 153-173. 12

Gay, L. R (1987). Educational Research: Competencies for 
Analysis and Application. (3rd Ed.) Columbus, Ohio, Merrill Pub. Co. 364.

Griffiths, L (1992). The Importance of Gender differences. In Hazel, C (1998). A Comparison of Gender-related Attitudes towards Mathematics between Girls in Single-sex and Co-educational Schools. A Master's Thesis Submitted to the University of Exeter

Hart, L. (1989). Classroom processes, sex of student, and confidence in learning mathematics. Journal for Research in Mathematics Education, 20(3), 242-260.

Heller, K. \& Parsons, J (1981). Sex differences in teachers'

evaluation feedback and students' expectancies for success in mathematics, Child Development, 52, 1015-1019.

Hyde, J. S., Fennema, E., Ryan, M., Frost, L.A., \& Hopp, C. (1990). Gender comparisons of mathematics attitudes and affect: A meta-analysis. Psychology of Women Quarterly, 14(3), 299-324.

Ho, H., Senturk, D., Lam, A.G., Zimmer, J. M., Hong, S., Okamoto, Y., Chiu, S., Nakazawa, Y., \& Wang, C. (2000). The affective and cognitive dimensions of math anxiety: A cross-national study. Journal for Research in Mathematics Education, 31(3), 362-379.

Lee, V. E and Rudyk, S (1986). Effect of Single-sex Secondary Schools on Students' Attitude and Participation. Journal of Educational Psychology. 77(4) 234-243

Linn, M. C. [1990]. Gender, mathematics and science: Trends and recommendations. Paper prepared for the summer institute for the Council of Chief State Schools Officers, Mystic, CT.

Lucy, S (1974). Why Gender differences are Important. In Hazel, C (1998). A Comparison of Gender-related Attitudes towards Mathematics between Girls in Single-sex and Co-educational Schools. A Master's Thesis Submitted to the University of Exeter

Ma, X. \& Kishor, N. (1997). Assessing the relationship between attitude toward mathematics and achievement in 
mathematics: A meta-analysis. Journal for Research in Mathematics Education, 28(1), 27-47.

Meyer, M. R. and Koehler, M.S. (1990) Internal Influences on Gender Differences in Mathematics. In: Mathematics and Gender, edited by E. Fennema and G. L. Leder. Pp. 60-95. New York: Teachers College.

McLeod, D. B. [1989]. Affective issues in mathematical problemsolving. Journal for Research in Mathematics Education, 10, 34-41

McLeod, D. B. [1992]. Affective issues in mathematical problemsolving. Some theoretical considerations. Journal for Research in Mathematics Education, 19, 134-141

Newman, R. S. (1990). Children's help-seeking in the classroom: The role of motivational factors and attitudes. Journal of Educational Psychology, 82(1), 71-80.

Nkani, A. K (1993). Achievements and Attitudes of Students towards Mathematics in the Ghanaian Secondary School and Preferred Intervention. A Master Thesis Presented to the University of Cape Coast. Ghana.

Norton, S. J., \& Rennie, L. J. (1998). Students' attitude towards mathematics in single-sex and coeducational schools. Mathematics Educational Research Journal, 10(1), 16-36.

Papanastatsiou, C. (2000). The effect of attitudes on mathematics outcomes. Paper presented at the 9th International Congress of Mathematics Education (ICME -9). Tokyo

Parsons, J. E; Alder, T. F; and Kaczala, C. M (1982). Socialization of Achievement Attitudes and Beliefs: Parental Influences. Child Development, 53: 310-339

Pedersen, Katherine, Dorothy R. Bleyer and Patricia B. Elmore. (1985). Gender and Mathematics Students. In Morin, G (2003) Does Sex Matter? Gender-Related Beliefs of Male and Female Junior High School Math Teachers. Monograph International Educational Administration and Policy Analysis. School of Education, Stanford University 
Pedersen, Katherine, Dorothy R. Bleyer and Patricia B. Elmore. (1995). Gender and Mathematics Students. In Morin, G (2003) Does Sex Matter? Gender-Related Beliefs of Male and Female Junior High School Math Teachers. Monograph International Educational Administration and Policy Analysis. School of Education, Stanford University

Heller, K. \& Parsons, J (1981). Sex differences in teachers' evaluation feedback and students' expectancies for success in mathematics, Child Development, 52, 1015-1019.

Rennie, L. J and Parker (1997): Effect of the classroom environment on learners' attitude towards mathematics. In Panji, C C. (2007). Students' Attitude Towards Mathematics in Malawi: Can They be Improved? University of Malawi

Ryan, A., \& Pintrich, P. R. (1997). "Should I ask for help?" The role of motivation and attitudes in adolescents' help seeking in math class. Journal of Educational Psychology, 89(2), 329341.

Sayers, R. (1994). Gender differences in mathematics education in Zambia. Educational Studies in Mathematics, 26(4), 389-403. Sherman, J. A (1980). Predicting Mathematics Grades of High School girls and boys: A further study. Contemporary Educational Psychology. 5: 249-255

Thomson, S., Cresswell, J., \& De Bortolli, L. (2004). Facing the future: A focus on mathematical literacy among Australian 15-year-old students in PISA 2003. Melbourne: ACER.

Thomson, S., \& Fleming, N. (2004). Summing it up: Mathematics achievement in Australian schools in TIMSS 200. (TIMSS Australia Monograph No 6). Melbourne: ACER.

Vermeer, H., Boekaerts, M., \& Seegers, G. (2000). Motivational and gender differences: Sixth-grade students' mathematical problem-solving behaviour. Journal of Educational Psychology, 92(2), 308-315.

Wong, N. (1992). The relationship among mathematics achievement, affective variables and home background. Mathematics Education Research Journal, 30(2), 171-191. 